\section{HYPNOTIC TREATMENT OF ASTHMA}

\section{REAL AND ILLUSORY RESULTS}

BY

\section{GRIFFITH EDWARDS,* M.A., B.M., B.Ch. \\ Formerly House Physician, Hammersmith Hospital}

Since 1910 an enormous amount has been written on the emotional aspects of asthma (Dunbar, 1954). This literature has, for the most part, been free from the shackles of scientific discipline. If there is to be any advance from this wealth of hypothesis, the next phase must be the collection of objective data (Leigh and Marley, 1956), and the exploitation of the tools of modern clinical research.

In recent years there has been a great advance in the application of ventilatory function tests to clinical problems (Gaensler, 1951). The present paper has the aim of exploring the possible usefulness of these tests when applied to the study of asthmatic patients treated by hypnosis.

In this study six patients admitted to hospital because of severe asthma were treated by hypnosis, and serial ventilatory function tests were made. The aim of such a small and uncontrolled series cannot be the collection of sufficient data to prove or disprove any theoryrather, its intention must be the limited one of seeing what problems are thrown up when a particular research tool is applied in a particular clinical situation.

\section{Methods}

Hypnotic Suggestion.-The patient was hypnotized and then given forceful suggestion that his asthma would gradually disappear, and that thenceforward any symptoms he might have would be very minor, would cause him no anxiety, and would never build up to a severe asthmatic attack. It was thought that to suggest immediate improvement in asthma of this severity would be to expect physiological impossibility: resolution of mucosal oedema and bronchial plugging is likely to take hours or days rather than minutes. Other than this suggestion, directed to the relief of anxiety, no form of psychotherapy was used. Suggestion under hypnosis was repeated on several days: the time for each session was 10 to 45 minutes. After this in-patient treatment no regular supportive out-patient hypnosis was given.

Ventilatory Function Tests.-The nomenclature used here is that recommended by Gandevia and Hugh-Jones (1957). Vital capacity (V.C.) and forced expiratory volume in one second (F.E.V.. $)$ were recorded. F.E.V..$_{1}$ is the maximum quantity of air that a patient can expire in one second, starting from the full inspiratory position. In a normal person the F.E.V. ${ }_{1} \%$ V.C. should be not less than 65 . This ratio has been discussed by Tiffeneau et al. (1949), Gaensler (1951), and Pemberton and Flanagan (1956). Indirect maximum breathing capacity (ind.M.B.C.) can be calculated by multiplying F.E.V. by the factor of 35 (Cara, 1953 ; Thomson and HughJones, 1958). On occasion, response to five minutes' inhalation of neb. adrenalin. et atropin. B.P. or neb. isoprenalin. B.P. as aerosol in oxygen by polymask was recorded. Interpretation of these tests in assessing completeness of treatment has been discussed by

*Now at the Maudsley Hospital, London.
Thomson and Hugh-Jones (1958). A response to the spray showed that there had been residual labile airways obstruction. Tests were carried out with a Gaensler type spirometer.

Selection of Patients.-Mild asthmatics were excluded from this study, and, at the other extreme, no patients were included who were judged to be in immediate danger of dying. All six accepted patients had severe continuous asthma for several days before admission. Response to aminophylline, adrenaline, etc. (subsequently referred to as " routine antispasmodics"), administered by the general practitioner, had been unsatisfactory, and emergency admission to hospital had been requested.

\section{Case 1}

A carpenter aged 36 had had asthma for seven years. Exacerbation occurred after contact with dusts and during fogs ("If I'm afraid of the fog, it hurts me ; if I'm not, it doesn't"); hay-fever ; family history of asthma.

First Admission (June 7 to 15, 1957). - On admission severe asthma (starting with hay-fever) had been present for three days. Patient was sweaty, distressed, and slightly cyanosed. Eosinophils 330/c.mm. (10\% of 3,300). On the night of admission he was treated with aminophylline intravenously and next morning by light hypnosis. Thereafter he had five hypnotic sessions, becoming symptom-free within three days. Eosinophils $250 / \mathrm{c} . \mathrm{mm}(5 \%$ of 5,000$)$ after one week.

Ventilatory Function Tests.-Table I shows the improvement during treatment. Despite complete clinical remission there was residual airways obstruction after the last hypnotic session, as shown by the improvement in ind.M.B.C. from 104 to $115 \mathrm{l}$./ min. that then took place after spray. The immediate effect of hypnosis was an improvement of 7, 0, 4, and $71 . / \mathrm{min}$. in ind.M.B.C. on four different occasions.

TABLB I.-Ventilatory Function Tests in Case 1 Before and After

\begin{tabular}{|c|c|c|c|c|}
\hline & v.c. & F.E.V.1 & $\mid \begin{array}{c}\text { F.E.V.C. } \\
\text { V.C. }\end{array}$ & $\begin{array}{l}\text { Ind. } \\
\text { M.B.C. }\end{array}$ \\
\hline $\begin{array}{llll}\text { On admission } & . . & \ldots & \ldots\end{array}$ & $3 \cdot 1$ & $1 \cdot 2$ & 40 & 42 \\
\hline \multirow{2}{*}{$\begin{array}{l}\text { Aefore final hypnotic session.. } \\
\text { Immediately after hypnosis ... } \\
\text { Immediately after } 7 \text { minutes' } \\
\text { spray } \\
\text {.. }\end{array}$} & $\begin{array}{l}5 \cdot 3 \\
5 \cdot 4\end{array}$ & $\begin{array}{l}2 \cdot 9 \\
3 \cdot 1\end{array}$ & $\begin{array}{l}54 \\
57\end{array}$ & $\begin{array}{r}99 \\
104\end{array}$ \\
\hline & $5 \cdot 1$ & 3.4 & 62 & 115 \\
\hline
\end{tabular}

Out-patient (June 15, 1957, to July 17, 1958).-Did well for over a year, with ind.M.B.C. readings of 117,107 , and $114 \mathrm{l} . / \mathrm{min}$. On March 10, 1958, ind.M.B.C. was 114, rising to 128 after spray: the reading of $1281 . / \mathrm{min}$. gave additional evidence that at the end of in-patient treatment considerable labile airways resistance had remained.

Second Admission (July 17 to 22, 1958).-Mild asthma treated with routine antispasmodics.

Out-patient (July 22 to October 6, 1958). -Seen 16 months after hypnotic treatment, he said that hypnosis had been most successful, and that there was " no comparison" with his previous state. He volunteered the opinion that the second hospital admission had been unnecessary. He had put on $21 \mathrm{lb}$. $(9.5 \mathrm{~kg}$.) in weight. His chest was normal on clinical examination, and yet ventilatory function tests showed considerable impairment, with V.C. 4.75 1., F.E.V.1 2.23 1., F.E.V.1 \% V.C. 49, and ind.M.B.C. $78 \mathrm{l} . / \mathrm{min}$.

\section{Case 2}

A builder aged 45 had had eczema for many years, hayfever for three years, and asthma of gradually increasing severity for one year. No family history.

Admission (June 23 to July 17, 1957).-On admission asthma had been continuous for several days. He was 
distressed, and had active eczema. Eosinophils $1,980 /$ c.mm. $(22 \%$ of 9,000$)$. He received four hypnotic sessions (poor subject) without any subjective or objective benefit. Subsequently he responded well to steroids.

Out-patient (July 17, 1957, to July 1, 1959). - He has been maintained on steroids with reasonably satisfactory control of his symptoms.

\section{Case 3}

A female clerk aged 33 had had asthma since the age of 15 . After desensitization she was free from symptoms for four years (aged 16-20). Asthma was again very troublesome at age 30-33, and further desensitization brought no benefit. She had no eczema or hay-fever. There was a family history of diabetes but none of asthma.

Out-patient (July 1 to 30, 1957).-Subjective benefit was gained from choline theophyllinate (" oxtriphylline"), $400 \mathrm{mg}$. q.d.s., with much improvement in ventilatory function tests. The F.E.V.1 \% V.C. of 77 after spray was interpreted as probably indicating complete remission: that much higher values

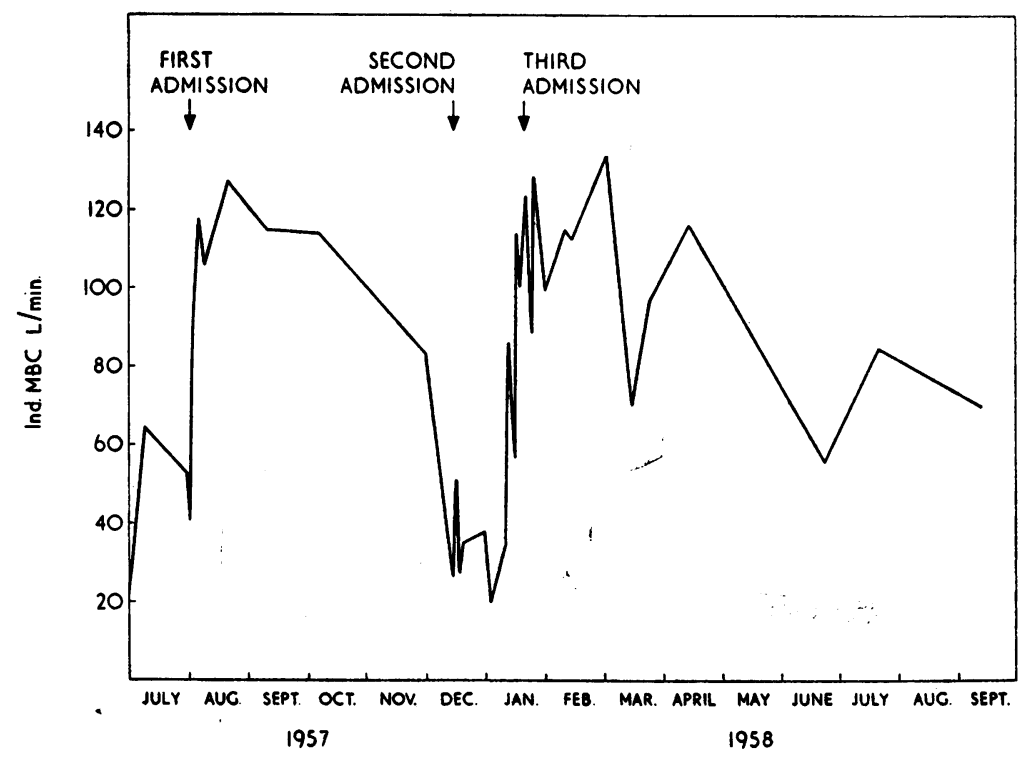
of ind.M.B.C. were obtained on subsequent occasions (Table II) shows that this interpretation was incorrect. The use of these tests is discussed in more detail below.

First Admission (July 30 to August 9, 1957).- On admission severe asthma had been continuous for the previous four days, and the patient was very distressed. Eosinophils 1,040/c.mm. (13\% of 8,000$)$. Treatment: She was given six sessions of deep hypnosis, routine antispasmodics tailing off by the second day. On discharge she was symptom-free and optimistic: eosinophils had fallen to $60 /$ c.mm. (2\% of 3,000$)$. Ventilatory function tests: Comparison of a reading made on the second day of admission with previous out-patient readings (Table III) showed improvement in ind.M.B.C. of $100 \%$, associated with clinical deterioration. However, serial readings during admission paralleled clinical improvement (Fig. 1), though the ind.M.B.C. of $116 \mathrm{l} / \mathrm{min}$. cn discharge was below her subsequent maximum of $134 \mathrm{l} / \mathrm{min}$.

Poor or negative immediate response to hypnosis contrasted with the almost invariably good immediate response to test spray.

Out-patient (August 9 to December 14, 1957).-For two months she claimed that she was " enjoying life as she hadn't done for years," though she "sometimes woke in the night

TABLE II.-Case 3, Showing High F.E.V. ${ }^{1} \%$ V.C. Without

\begin{tabular}{|c|c|c|c|c|c|}
\hline & & v.c. & F.E.V.V.1 & $\underset{\text { V.C.C. }}{\text { F.E.V }} \%$ & $\begin{array}{l}\text { Ind. } \\
\text { M.B.C. }\end{array}$ \\
\hline $\left.\begin{array}{c}\text { Readings after } \\
7 \text { days ' choline } \\
\text { theophyllinate }\end{array}\right\}$ & $\begin{array}{l}\text { Before spray } \\
\text { After " }\end{array}$ & $\begin{array}{l}2.7 \\
2.9\end{array}$ & $\begin{array}{l}1 \cdot 8 \\
2 \cdot 3\end{array}$ & $\begin{array}{l}65 \\
77\end{array}$ & $\begin{array}{l}65 \\
80\end{array}$ \\
\hline $\left.\begin{array}{l}\text { Subsequent } \\
\text { highest readings }\end{array}\right\}$ & $\begin{array}{l}\text { Before ", } \\
\text { After }\end{array}$ & $\begin{array}{l}4.9 \\
4.7\end{array}$ & $\begin{array}{l}3 \cdot 8 \\
4 \cdot 0\end{array}$ & $\begin{array}{l}78 \\
85\end{array}$ & $\begin{array}{l}134 \\
140\end{array}$ \\
\hline
\end{tabular}

TABLB III.-Case 3, Showing Comparison of Lung-function Tests With Clinical State (Figures in Litres)

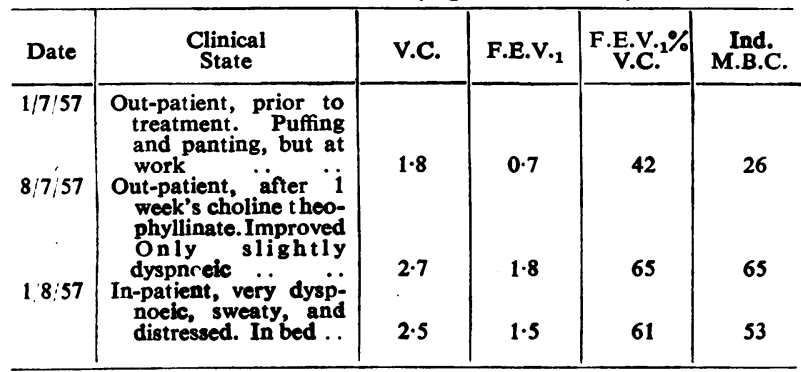

with what previously would have been an attack." One to two months after discharge she was obviously deteriorating, though she claimed to be as well as ever.

Second Admission (December 14 to 24, 1957) and Third Admission (January 6 to 21, 1958).-On admission severe asthma had been continuous for the previous four days. Eosinophils 2,400/c.mm. (20\% of 12,000). Routine antispasmodics brought poor response. She was allowed home for Christmas and then returned for treatment with steroids: to prednisone, $10 \mathrm{mg}$. six-hourly, she made an excellent response and went into complete clinical remission. Eosinophils fell to $450 \mathrm{c}$. $/ \mathrm{mm}$. (5\% of 9,000 ). Ventilatory function tests : Ind.M.B.C. was initially at a lower level than on the first admission. The ind.M.B.C. in her three admissions is shown in Fig. 1, and the rates of response compared in Fig. 2.

Out-patient (January 21, 1958, to August 1, 1959).Discharged from the ward on maintenance with prednisone $5 \mathrm{mg}$. daily, she was in remission for two months (ind.M.B.C. rose to $134 \mathrm{l} . / \mathrm{min}$.), but at the end of that time she again became very wheezy, with ind.M.B.C. falling to $71 \mathrm{1} . / \mathrm{min}$.

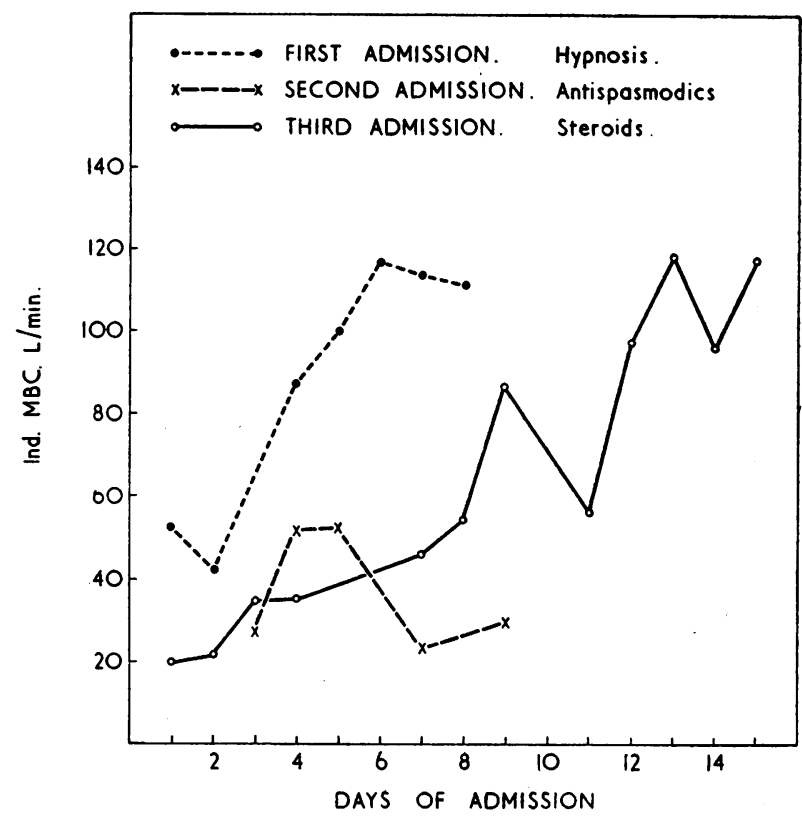

Fia. 2.-Case 3. Ind.M.B.C. compared for three admissions. 
Since then she has been maintained on steroids, the dose varying according to need-for example, prednisone 2.5-30 mg./day. For the most part she has been symptom-free, though for short spells she has been very wheezy. Ind. M.B.C. has been between 70 and $1001 . / \mathrm{min}$. She developed diabetes mellitus after about a year of steroid therapy. This has been difficult to control, as the variation in steroid dosage affects the insulin needs.

\section{Case 4}

A male executive aged 33 had had asthma since he was 5 years old. He was temporarily free from symptoms while in R.A.F. air crew, but since then had had asthmatic attacks winter and summer, but no eczema or hay-fever. There is no relevant family history.

Admission (August 2 to 11, 1957).-For ten days previous to admission he had continuous asthma, and on admission moderate continuous dyspnoea without being greatly distressed. Eosinophils $1,080 \mathrm{c} . / \mathrm{mm}$. $(18 \%$ of 6,000$)$. He received five sessions of deep hypnosis, and was weaned

TABLB IV.-Case 4, Showing Comparison of Lung-function Tests With Clinical State (Figures in Litres)

\begin{tabular}{|c|c|c|c|c|c|}
\hline Date & $\begin{array}{c}\text { Clinical } \\
\text { State }\end{array}$ & v.c. & F.E.V.'1 & $\underset{\text { V.E.V. }}{\text { V. }{ }^{1} \%}$ & $\begin{array}{l}\text { Ind. } \\
\text { M.B.C. }\end{array}$ \\
\hline $\left.\begin{array}{c}2 / 8 / 57 \text { (day of } \\
\text { admission) }\end{array}\right\}$ & $\begin{array}{c}\text { Moderately severe } \\
\text { dyspnoea }\end{array}$ & $2 \cdot 2$ & 0.8 & 35 & 27 \\
\hline $\left.\begin{array}{l}11 / 8 / 57 \text { (day } \\
\text { of discharge) }\end{array}\right\}$ & Symptom-free .. & 4.8 & 3.7 & 76 & 129 \\
\hline $\left.\begin{array}{l}\text { 23/8/57 (first } \\
\text { O.P.P. attend- } \\
\text { ance) }\end{array}\right\}$ & Slightly wheezy .. & 3.5 & $1 \cdot 4$ & 39 & 47 \\
\hline $\left.\begin{array}{l}\text { 6/10/58 (O.P. } \\
\text { attendance) }\end{array}\right\}$ & Symptom-free .. & 4.0 & $2 \cdot 3$ & 58 & 81 \\
\hline
\end{tabular}

from hand spray by the second day. He was taught the technique of autohypnosis, and it was suggested that he could use this as a method of relaxation to abort asthmatic attacks. He was discharged symptom-free. Ventilatory function tests: Response is summarized in Table IV, improvement in ind.M.B.C. paralleled clinical improvement, but continued after the patient considered himself to be

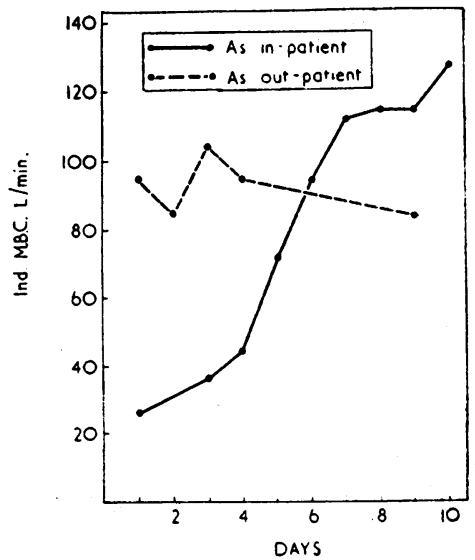

FIo. 3.-Case 4. Change in ind.treatment. Continuous line: response as in-patient. Broken line: response as out-patient. M.B.C. during intermittent hypnotic symptom-free. Readings on discharge did not respond to spray, and, with F.E.V.1 \% V.C. of 76 , probably indicated complete remission. Immediate responses to hypnosis were always poor with this patient.

Out-patient (August 11 to October 6, 1957). - Within days of returning home he developed moderately severe asthma. Ind.M.B.C. fell to $47 \mathrm{l}$./ min., but three weeks later it had risen to $1131 . / \mathrm{min}$. Five further sessions of hypnosis were then given, and, though there was subjective benefit, ventilatory function tests did not improve. Fig. 3 compares his in-patient and out-patient response. A year later he stated that he had been " $500 \%$ better than in previous years." On auscultation there was no wheeze. Ventilatory function tests, however, were much impaired (Table IV).

\section{Case 5}

A schoolboy aged 14 had had asthma since 9 months old, but no eczema or hay-fever. There was a family history of asthma.
Admission (August 30 to October 2, 1957).-Asthma had been continuous for five days before he was admitted, and on admission symptoms were moderately severe (mildest of six cases). A poor hypnotic subject, his remission was slow and incomplete subjectively and objectively despite 23 sessions. Eosinophils remained above 1,000/c.mm. Ventilatory function tests confirmed incompleteness of remission: immediate response to hypnosis was usually a slight fall in ind.M.B.C.

Out-patient (October 2 to December 12, 1957).-His asthma was "as bad as ever": he relapsed completely within 12 days of going home.

\section{Case 6}

A female clerk aged 25 had had asthma and hay-fever since the age of 10 . She was desensitized when 20 , with improvement lasting two years. There was a strong family history of asthma.

Admission (September 24 to October 6, 1957).--Severe asthma had been continuous for three weeks before she was admitted. On admission dyspnoea was severe and continuous. Eosinophils $240 /$ c.mm. ( $2 \%$ of 12,000$)$. Chest $x$-ray examination normal. Hypnosis was given (seven sessions, deep state), and she was symptom-free within three days. Eosinophils $80 /$ c.mm. $(1 \%$ of 8.000$)$ on discharge. Ventilatory function tests: Values reached (Table V) were probably normal for her small size. F.E.V.1 \% V.C. was above 80 on five consecutive days. Tests continued to improve after remission subjectively was complete. Immediate effects of hypnosis were slight and inconstant.

Out-patient (October 6, 1957, to October 6, 1958). -She relapsed within a few days of returning home. Two weeks later she was wheezing though still going about her work. Tests showed then that V.C. was slightly lower and ind. M.B.C. slightly higher than on first entering hospital (Table V). Symptoms then fluctuated, but in her own opinion she

TABLB V.-Case 6, Showing Comparison of Lung-function Tests With Clinical State (Figures in Litres)

\begin{tabular}{|c|c|c|c|c|c|}
\hline Date & $\begin{array}{c}\text { Clinical } \\
\text { State }\end{array}$ & v.c. & F.E.V. & $\begin{array}{c}\text { F.E.V. }{ }^{\text {V.C. }} \% \\
\text { V.C }\end{array}$ & $\begin{array}{l}\text { Ind. } \\
\text { M.B.C. }\end{array}$ \\
\hline $\left.\begin{array}{c}24 / 9 / 57 \text { (day of } \\
\text { admission) }\end{array}\right\}$ & $\begin{array}{c}\text { Moderately severe } \\
\text { asthma. Having } \\
\text { to stay in bed .. }\end{array}$ & 1.8 & 0.5 & 30 & 19 \\
\hline $\left.\begin{array}{c}6 / 10 / 57 \text { (day of } \\
\text { discharge }\end{array}\right\}$ & Symptom-free .. & 3.0 & 2.5 & 83 & 89 \\
\hline $\left.\begin{array}{l}21 / 10.57 \text { (first } \\
\text { O.P.attend- } \\
\text { ance) }\end{array}\right\}$ & $\begin{array}{c}\text { Better than } 24 / 9 / 57 \\
\text { Able to do her } \\
\text { work .. } \quad . .\end{array}$ & 1.7 & 0.7 & 42 & 26 \\
\hline $\left.\begin{array}{r}\text { 6/10/58 (O.P. } \\
\text { attendance) }\end{array}\right\}$ & $\begin{array}{l}\text { Free from asthma- } \\
\text { tic symptoms, } \\
\text { but with apical } \\
\text { tuberculosis .. }\end{array}$ & 2.4 & 1.9 & 78 & 66 \\
\hline
\end{tabular}

was "about $50 \%$ better than in previous years." She came to the casualty department in May, 1958, and derived immediate subjective benefit from hypnosis (one session). A year after admission she was free from symptoms, but tests showed subnormal values (Table V). During that year she had been maintained intermittently on steroids, and in October she was found to have developed pulmonary tuberculosis: her infant subsequently died of tuberculous meningitis.

\section{Discussion}

\section{Methods of Assessment}

Three methods are available for assessing the state of a patient's asthma: (1) subjective, the patient's own testament; (2) quasi-objective, the use of a stethoscope ; (3) objective, the use of ventilatory function tests.

The first method has one advantage, for the respiratory function of an asthmatic may vary from hour to hour, and therefore the patient's own overall assessment of how he has fared during the previous month may some- 
times be a truer measure of his asthma than are the doctor's isolated observations made at a monthly clinic. For instance, in Case 3 the patient after hypnotic treatment said that she then woke with "what previously would have been an attack"-an improvement that certainly could not be measured in a clinic.

On the other hand, airways obstruction may be present (as detectable by ventilatory function tests) without the patient being aware of disability (Beale et al., 1952). By producing a degree of euphoria, hypnosis is likely to accentuate the inadequacy of introspection. This was seen in Case 3, when, at a time when the patient was deteriorating and had a loud wheeze, she declared that she was "as well as ever." Indeed, the four patients who responded well to hypnosis all showed on several occasions a complete absence of symptoms and of auscultatory signs at a time when ventilatory function tests left no doubt that considerable physiological impairment (airways obstruction) remained.

It follows, therefore, that if the potentialities of hypnotic treatment are to be correctly understood, physiological must be differentiated from psychological changes. Cases will otherwise be claimed as "cures" when all that has been really achieved is unawareness of disability: this may account for some of the optimistic claims that have been made for hypnotherapy (Magonet, 1955 ; Fry, 1957 ; Stewart, 1957). Evident in much of the literature on the treatment of asthma is the fallacious assumption that suppression of the asthmatic's symptoms is equivalent to the relief of his disordered respiratory physiology. Similarly, the statement that abounds in the psychiatric literature to the effect that particular forms of psychological stress can "cause" an asthmatic attack cannot, in the absence of objective testing, be taken as semantically equivalent to a statement that psychological stress has caused physiological abnormality in lungs that were free from physiological abnormality prior to the stress. In fact, it has yet to be proved that such stresses can cause, as opposed to exacerbate, physiological abnormality.

However, the therapeutic usefulness of hypnosis should be recorded even when the main effect it has produced has been simply a lack of awareness of disability. Such a result was seen in Case 4 when, after out-patient hypnosis, the patient said that he had derived much benefit, though spirometry showed no corresponding improvement.

\section{Objective Tests Available}

A shortcoming in the use of V.C. and F.E.V. recordings is that accurate data on what should be the individual patient's normal values are not available from tables. This very real shortcoming can perhaps be repaired once the patient has been studied over a period of weeks ; for it is then, on the basis of certain criteria, usually possible to assert that certain values of V.C. and F.E.V..$_{1}$ are his normal (maximal). The criteria for this assertion are that the graphs of function should have climbed beyond the point of "clinical remission" and reached a plateau with F.E.V. $.1 \%$ V.C. well above 65 , and that there should then be a lack of response to spray. These values of V.C. and F.E.V.1 can then (with some degree of confidence) be used to measure completeness of remission on subsequent occasions. As F.E.V.r still rises after V.C. has become stationary, F.E.V..$_{1}$ is the better single test. The significance of F.E.V.r is perhaps more familiar when it is converted into terms of ind.M.B.C. This is the only excuse, and not a very good one, for this conversion. Graphs of ind.M.B.C. have therefore been preferred in giving the simplest picture of the asthmatic's progress.

The use of the ratio F.E.V..$_{1} \%$ V.C. has been proposed as another way of circumventing the difficulty of not knowing a particular patient's normal values for V.C. and F.E.V.1, for if it can be accepted that a normal person has a F.E.V./V.C. ratio of greater than $65 \%$ whatever the (unknown) normal values for each of the separate parameters V.C. and F.E.V. $\cdot_{1}$, then a simple objective test is available with which it can be stated whether a patient is completely treated. Thomson and Hugh-Jones (1958) have studied the changes in F.E.V. $\%$ V.C. during recovery from asthma. It is important to establish whether F.E.V. 1 \% V.C. provides a reliable index of completeness of treatment, and, on the whole, its usefulness was confirmed with the present patients. But if isolated readings were regarded as decisive the test became misleading (Table II), and in assessing completeness of remission it was safer to rely on the pattern of tests found over several days. The significance of a low F.E.V. \% V.C. was interpreted more confidently than the high readings: a low result must imply impaired function.

The perfect test of ventilatory function would be an index whose fall-off bore a linear relationship to the, at present, nebulous concept " quantity of asthma." But even this ideal test would not be expected to bear a linear relationship to "ventilatory well-being," which is as much a function of the psyche as of the lungs.

The value of the eosinophil count as an index of response to treatment is poorly understood: Feinberg et al. (1951) found that response to steroids did not correlate with drop in eosinophil count.

\section{Results with Hypnosis}

As has already been stated, the validity of claims made for any form of treatment cannot be assessed on the results obtained with a small uncontrolled series. Caution and reservation are particularly necessary when claim is made for success in treating asthma ; for here one is studying a disease having a notoriously unpredictable course, and any "response to treatment" may be no more than the lucky coincidence of a natural remission and therapeutic effort. The design of the series on which the present paper is based fulfils none of the criteria proposed by Leigh (1953) as being necessary in a properly controlled evaluation of any therapeutic method for asthma ; rather, the results should be taken only as suggesting some of the problems of assessment that will occur when hypnosis is put to the test of formal clinical trial.

An imponderable factor in discussing results with hypnosis is the skill or lack of skill of the individual hypnotist.

Immediate Results.-The patients often immediately felt better. Objectively, the immediate benefit was seldom significant, and as the suggestion given to the patients was of gradual rather than abrupt improvement, this result was not unexpected. That quite often a fall rather than an increase in function was obtained was an interesting and unexplained result of hypnosis.

Results During the Period of Hospital Admission.Part of the difficulty in evaluating any treatment of asthma is that hospital admission may in itself amount 
to treatment. This is suggested by the results shown in Fig. 3, where the response of Case 4 to in-patient is compared with that to out-patient hypnotherapy: in both instances he benefited subjectively, but only when he was in the ward did hypnosis produce objective benefit. Strictly speaking, a "control" series should therefore consist of patients receiving hospital admission as the only treatment-probably an ethical impossibility with severe asthma. Further, to define strictly the contribution made by hypnosis to hypnosuggestion, comparison is required between patients treated with hypnosis and a group treated by unaided suggestion. Speed of remission with hypnosis was often as rapid as with conventional treatment. Probably a maximum rate of recovery (dictated not only by spasm but by mucosal oedema and bronchial plugging) cannot be exceeded whatever form of therapy is used. In Case 3 opportunity arose to compare rates of remission with hypnosis, antispasmodics, and steroid therapy (Fig. 2). Completeness of remission in the six cases while in the ward may be summarized as: two cases subjectively and objectively incomplete, one of these totally failing to respond to hypnosis ; two cases subjectively complete but objectively incomplete; and two cases subjectively and objectively complete.

Results on Follow-up.-Results, with three patients out of five relapsing immediately on return home, are unimpressive. Yet, of these three patients who immediately relapsed, two quickly returned to a good clinical state (and the third was not followed up). At the end of a year, two out of the four patients who had had a good response to hypnosis in the ward still claimed benefit from hypnosis. Of the four patients followed up who had shown the good response, two were readmitted with asthma. The reasons that may bring an asthmatic into hospital are complex. Admission is the end-result of a number of opinions (often arbitrary and subjective) expressed by patient, general practitioner, and housephysician, and is not a quantitative measure of asthma. That Case 1 was readmitted when he himself considered that his asthma was not severe enough to require admission emphasizes how difficult it is to assess the significance of an admission. Another aspect of this complexity was seen in Case 3, where objective tests on an occasion when the patient required admission were not as severely impaired as they had been while she was still at workan example of " severity" of asthma depending not only on quantity of airways obstruction but also on quantity of despair and fatigue. Certainly it would be difficult to analyse the significance of a long-term count of the number of times that a patient was put into hospital.

\section{Rationale of Hypnosis}

Hypnotic suggestion has now been used for the treatment of asthma by workers holding many different views on the nature of the disease.

In the cases reported in this paper, hypnosis was used simply to reinforce suggestion that the asthma would remit. Whether suggestion (or hypnosuggestion) seems a rational therapy in asthma must depend partly on one's concept of the aetiology of asthma and of the so-called psychosomatic diseases in general-a subject the philosophic and logical difficulties of which have been reviewed by Lewis (1954). At one pole is the view held by the analysts, that asthma is a neurosis resulting from parent-dependence (French et al., 1941): an opposed view is expressed by Rees (1956), who formulates the theory that asthma is a multifactorial disease with both physical and (non-specific) psychological factors in its aetiology. This latter view is also the one expressed by Leigh (1957) in an extensive review of the psychological aspects of asthma. The non-specificity of the psychological setting was stressed by Gendrot (1953).

In the present study hypnosis was used on the assumption that the primary aetiology of asthma is always somatic (and untreatable by psychotherapy), but that the severity of this disease may be potentiated by anxiety, including anxiety about asthma. The analogy is to angina pectoris, where fear of pain and the resulting anxiety may bring on an attack, though the somatic nature of the coronary narrowing is not doubted. Asthma is not the respiratory analogue of the effort syndrome.

However, even if one does not accept any particular formulation of the aetiology of asthma, there is ample evidence for the pragmatic assertion that suggestion is of benefit in treating this disease: this is probably one of the few facts about asthma that go uncontested. The reinforcement of suggestion by the methods of hypnosis therefore seems a logical extension of common practice: hypnosis cannot be regarded as a radical departure from more usual therapy, but rather a means of reinforcing the strong element of suggestion that is present in "physical" forms of asthma treatment. The element of suggestion in most of these methods was stressed by Hurst (1943), and was shown quite strikingly in the M.R.C. (1956) cortisone trial, where difficulty was encountered in weaning patients from dummy cortisone. Wide-field irradiation (Scott, 1936), attention to underclothing combined with the proper employment of cold baths and rough towels (Harrington, 1936), and the avoidance of strawberries and champagne (unpublished papers of a nineteenth-century physician) have all had their successes.

How often and how deeply should the patient be hypnotized? In the present study the patients were given a short course only (while in hospital), with no supportive out-patient hypnosis, except for Case 4 (four sessions) and Case 6 (one session).

Dangers and Disadvantages of Hypnosis.-The theoretical dangers of hypnosis have often been stated, but in a survey conducted among practising psychiatrists few untoward effects were reported (Wolberg, 1956). The subcommittee of the British Medical Association that reported on the use of hypnosis was of the opinion that dangers, though often exaggerated, do exist (Brit.med.J., 1955).

\section{Hypnosis versus Steroids}

In an asthmatic with mild symptoms adequately controlled with antispasmodics hypnosis has little to offer. It is in terms of the patient with severe asthma that the potentialities of hypnosis should be assessed, and this must imply the evaluation of hypnosis as against steroids.

With steroids there are now available powerful drugs for treating severe asthma, and giving tablets is certainly simpler than inducing hypnosis. But the dangers that may follow adrenal suppression are reported not infrequently in the medical press; as an example may be taken the report of Brockbank et al. (1957), of seven asthmatics dying while on steroid therapy. If hypnosis could be shown (even in a small proportion of cases) to be a valid alternative to steroids, then hypnotherapy for asthma should be more widely used. The availability 
of steroids makes a full and objective assessment of the potentialities of hypnosis more rather than less urgent.

\section{Summary and Conclusions}

Six patients admitted to hospital with severe asthma were treated by hypnotic suggestion. Five were subsequently followed up for not less than one year.

Patients were assessed both by their subjective testament and objectively by spirometry: it was found that an adequate assessment could be based only on a combination of these methods. With this double assessment it was apparent that hypnosis benefited a patient in one of two entirely different ways - either by effecting physiological improvement (decrease of airways resistance) or by producing psychological improvement (decreased awareness of airways resistance). The distinction between these two responses has not often been adequately stressed. The implications of these findings for psychosomatic theory are discussed.

While in hospital one patient failed completely to respond to hypnosis, and one responded poorly. Four had subjectively complete remissions, but in only two of these was remission objectively complete. Immediate response to hypnosis (before and after sessions) was usually poor, but this could be explained by the content of the suggestion. Speed of remission could be as fast with hypnosis as with physical methods.

Three patients relapsed within days of going home, but two of these again went quickly into remission. Of the four patients originally responding well, two thought that their condition during the year after was much better than in previous years. Two out of these four patients were readmitted because of asthma.

These results cannot be interpreted as valid evidence for or against the value of hypnosis: an uncontrolled series of six patients can be regarded only as pilot study. The results do, however, strongly suggest that a controlled clinical trial of hypnosis would repay the effort. The particular value of hypnosis may be as an alternative to steroid treatment.

I wish to thank Dr. C. M. Fletcher and Dr. P. Hugh-Jones for their encouragement and criticism. My thanks are also due to them and to Dr. J. G. Scadding for permission to report on their patients, and to Miss Heather Macleish, who undertook much of the spirometry.

\section{REPERENCES}

Beale, H. D., Fowler, W. S., and Comroe, J. H., jun. (1952). J. Allergy, 23, 1 .

Brit. med. J., 1955, 1, Suppl. p. 190.

Brockbank, W., Savidge, R. S., and Brebner, H. (1957). Lancet, 2, 666 .

Cara, M. (1953). Poumon, 9, 406.

Dunbar, H. F. (1954). Emotions and Bodily Changes, 4th ed. Columbia Univ. Press, N.Y.

Feinberg, S. M., Dannenberg, T. B., and Malkiel, S. (1951). J. Allergy, 22, 195.

French, T. M., Alexander, F., et al. (1941). Psychogenic Factors in Bronchial Asthma, Psychosomatic Medicine Monographs IV. National Research Council, Washington, D.C.

Fry, A. (1957). Brit. med. J., 1, 1323.

Gaensler, E. A. (1951). Amer. Rev. Tuberc., 64, 256.

Gandevia, B., and Hugh-Jones, P. (1957). Thorax, 12, 290

Gendrot, J. Ä. (1953). Evolut. psychiat., p. 493.

Harrington, F. T. (1936). The Treatment of Asthma. Lewis, London.

Hurst, A. (1943). Brit. med. J., 1, 403.

Leigh, D. (1953). Int. Arch. Allergy, 4, 227.

Leigh, (1957). Med. Press, 238, 153

二 and Marley, E. (1956) J. psychosom. Res., 1, 128.

Lewis, A. (1954). Recenti Progr. Med., 16, 434.

Magonet, A. P. (1955). Hypnosis ịn Asthma. Heinemann London.

Medical Research Council (1956). Lancet, 2, 798.

Pemberton, J., and Flanagan, E. G. (1956). J. appl. Physiol., 9 291.
Rees, L. (1956). J. psychosom. Res, 1, 98.

Scott, S. G. (1936). Brit. med. J., 1, 132.

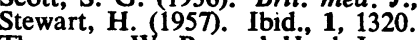

Thomson, W. B., and Hugh-Jones, P. (1958). Ibid., 1, 1093

Tiffeneau, R., Bousser, J., and Drutel, P. (1949). Paris méd., 137, 543.

Wolberg, I.. R. (1956. In Progress in Psychotherapy, edited by Frieda Fromm-Reichmann and J. L. Moreno. Grune and Stratton, N.Y.

\section{A CASE OF CAT PHOBIA*}

TREATMENT BY A METHOD DERIVED FROM EXPERIMENTAL PSYCHOLOGY

BY

H. L. FREEMAN, $\dagger$ M.A., B.M., B.Ch., D.P.M.

Formerly Registrar, Bethlem Royal and Maudsley Hospital, London

AND

D. C. KENDRICK, B.A., Ph.D., Dip.Psychol.

Lecturer in Psychology, Institute of Psychiatry, University of London

In recent years a new therapeutic technique-reciprocal inhibition (Wolpe, 1958)-derived from the field of experimental psychology has become available in psychiatry. The concept was originally introduced by Sherrington, and refers to situations in which the elicitation of one response causes a reduction in the strength of evocation of another, simultaneous response. When stimuli producing incompatible responses are present at the same time, the response that is stronger will cause the reciprocal inhibition of the other.

The aim of the technique is to make a response antagonistic to anxiety to occur in the presence of anxiety-evoking stimuli. There is a superimposition of non-anxiety responses to these stimuli, which tends to weaken the bonds between them and the anxiety responses, through lack of reinforcement.

\section{Background}

Research over the past thirty years into psychodynamically orientated therapy has generally been disappointing. Most of the findings have either been unreliable, in the sense that they have not been or could not be repeated, or have failed to provide any evidence of positive benefit. Glover (1955) has disavowed any claims for the therapeutic usefulness of psychoanalytic methods. However, there is an increasing quantity of material concerned with therapeutic techniques which have been derived from conditioning and learning theory, and claiming some success. Unfortunately, as yet, no controlled study has been attempted to compare the efficacy of any psychotherapeutic techniques against those of behaviour therapy. The techniques derived from learning theory have two main advantages over those derived from psychoanalytic theory: $(a)$ they can be tested experimentally, and $(b)$ under certain circumstances the behaviour disorders can be experimentally manipulated in a predictable manner (Yates, 1958).

The modern learning theorist considers that neurotic symptoms are learned patterns of behaviour (Eysenck, 1959) which are unadaptive in the social sense but designed to relieve anxiety in the individual. A phobic symptom probably represents a surplus conditioned

*Based on a paper read at the Annual Conference of the British Psychological Society, Hull, April, 1960

tAt present, Senior Registrar, Littlemore Hospital, Oxford. 